\title{
¿Coastal Trapped Wave Propagation along the Southwest African Shelf as Revealed by Moored Observations
}

\author{
Tim Junker, Volker Mohrholz, MARTin Schmidt, AND Lydia SiEgFried \\ Leibniz-Institut für Ostseeforschung Warnemünde, Rostock, Germany \\ ANJA VAN DER PLAS \\ National Marine Information and Research Centre, Swakopmund, Namibia
}

(Manuscript received 13 March 2018, in final form 28 December 2018)

\begin{abstract}
Coastal trapped waves (CTWs) that propagate poleward along the southwest African shelf potentially leak energy from lower latitudes into the Benguela Upwelling System (BUS). Thus, in addition to local winds, these waves provide an important remote forcing mechanism for the upwelling region. The present study aims at elucidating the nature of CTWs in the northern BUS. To this end, we make use of multisite velocity observations from the Namibian shelf $\left(18^{\circ}, 20^{\circ}, 23^{\circ} \mathrm{S}\right)$ and examine the alongshore velocity signal for signatures of CTWs by means of wavelet methods. We found that a substantial amount of energy is concentrated within a submonthly to subseasonal frequency band (10-50 days). Based on the coherence and phase spectra of the alongshelf currents, we provide evidence for a predominantly southward phase propagation and establish typical time and length scales of CTWs in the region. It turns out that their properties differ significantly within a few hundred kilometers along the coast. A comparison of the results with theoretical dispersion curves shows that this difference may be explained by variations in the bottom topography. Finally, we investigate the coupling of the alongshore currents with the coastal and equatorial wind stress and highlight regions of potential wave generation.
\end{abstract}

\section{Introduction}

Subinertial fluctuations of currents and sea level with periods of a few days to weeks have been demonstrated along various coasts of the continents. Most of this variability was attributed to the existence of coastal trapped waves [CTWs; e.g., Allen (1980) and references therein]. These waves are most efficiently generated by fluctuations in the alongshore winds and provide-in addition to the local atmospheric forcing-an important remote forcing mechanism (Csanady 1997).

Along the southwest African coast, CTWs have received particular attention as they provide a dynamical linkage between the tropical Atlantic and the subtropical Benguela Upwelling System (BUS; e.g., Polo et al. 2008; Lübbecke et al. 2010; Bachèlery et al. 2016). Based on

¿ Denotes content that is immediately available upon publication as open access.

Corresponding author: Volker Mohrholz, volker.mohrholz@ io-warnemuende.de altimetry data, several studies have presented evidence for the propagation of CTWs along the southwest African coast in the intraseasonal (30-90 day) to seasonal frequency range [among them, Schouten et al. (2005); Polo et al. (2008)]. These waves are thought to be generated by the interaction of an equatorial Kelvin wave with the African coast. On interannual time scales, CTWs certainly play an important role in the generation of anomalous warm events (Benguela Niños) in the Benguela region (Florenchie et al. 2003; Rouault et al. 2007; Lübbecke et al. 2010; Rouault et al. 2018). Based on numerical experiments, Bachèlery et al. (2016) showed that the interannual variability of the Benguela region is driven to about $90 \%$ by remote effects.

In addition to the equatorial forcing, CTWs may also be generated by local wind fluctuations in the Benguela system on synoptic time scales of a few days to weeks. Waves triggered locally impact the circulation in the upwelling system substantially, including the arrest of the equatorward coastal jet and the generation of a poleward undercurrent (Fennel 1999; Fennel et al. 2012). Thus, CTWs generated within the Benguela system on relatively short time scales support the southward advection of tropical 
waters even in the absence of a tropical forcing (Fennel et al. 2012). The contribution of CTWs to the coastal variability in the Benguela region on relatively short time scales, however, is not well investigated. Some studies have anticipated the existence of CTWs along the southwest African coast from spatial current pattern or energy spectra on time scales of a few days to weeks [Vangriesheim et al. (2005) off Angola; Hagen (1979) and Lass and Mohrholz (2005) off Namibia]. However, despite the strong dynamical relevance of CTWs for the region, direct observations of these waves in the northern Benguela region have not been reported until now. The reason is most likely the scarcity of contemporaneous current measurements and sea level records (Woodworth et al. 2007) along the southwest African coast.

In this study, we present for the first time concurrent velocity observations from three sites in the northern BUS $\left(18^{\circ}, 20^{\circ}, 23^{\circ} \mathrm{S}\right)$. In contrast to altimeter data, these observations allow in particular to investigate highfrequency processes $\left[>(20 \text { days })^{-1}\right]$. Based on the phase relation between the different sites, we establish typical time and length scales of poleward-propagating CTWs and discuss differences in the coherence pattern along the shelf.

\section{Database}

\section{a. Current data}

The current data are obtained from three hydrographic long-term moorings deployed along the Namibian shelf between $18^{\circ}$ and $23^{\circ} \mathrm{S}$; see Fig. 1 . The moorings are referred to as LT18, LT20, and LT23 according to their latitude. They are separated alongshore by about 250 (LT18, LT20) and $350 \mathrm{~km}$ (LT20, LT23), respectively. All three moorings are equipped with an upward-looking ADCP (RDI-Workhorse $300 \mathrm{kHz}$ ) mounted close to the bottom capable of observing the water column up to a depth of $16 \mathrm{~m}$ with a vertical resolution (bin size) of $4 \mathrm{~m}$.

The ADCP data were recorded at hourly intervals, and the velocity data were compensated for magnetic declination after recovery. Subsequently, the records were quality checked, and suspicious data were rejected. Gaps in the data lasting fewer than $5 \mathrm{~h}$ were interpolated linearly.

To optimally examine the velocity data for signatures of CTWs, the current's direction needs to be divided into an alongshore and a cross-shore component. We have to admit that a calibration of the ADCPs' compasses in a suitable environment was not always possible for each deployment due to logistic constraints. Thus, instead of referring to the coastline azimuth for the determination of the two velocity components, we make use of the

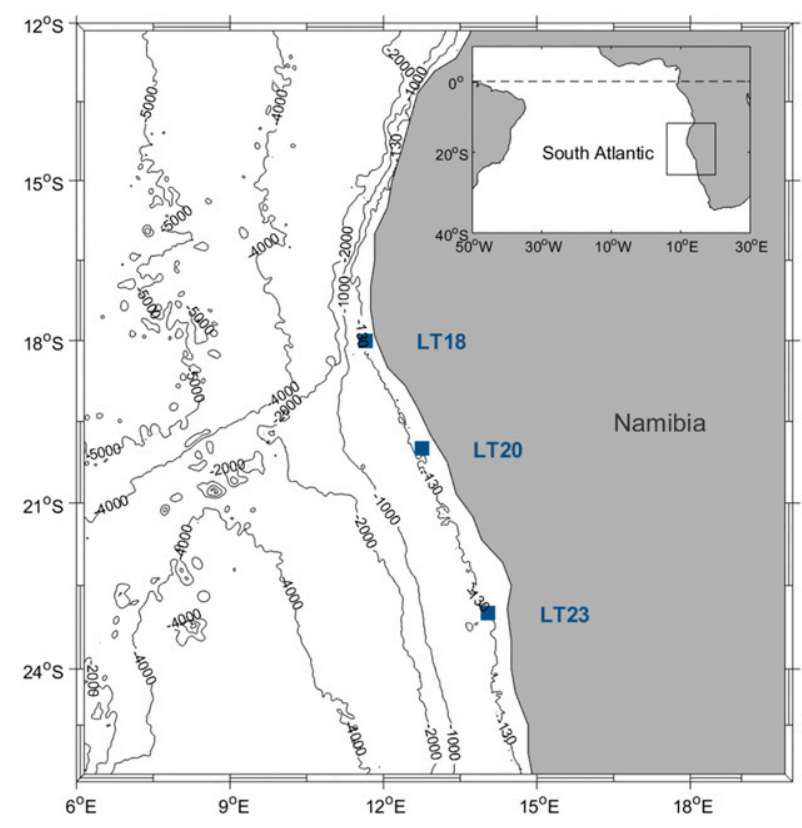

FIG. 1. Map of the study area showing the location of the three moorings.

principal axes of current velocity variance (Emery and Thomson 2014). The advantage of this method is that the current components become almost independent of compass errors (about $\pm 5^{\circ}$ for calibrated devices) and the magnetic deviation (about $13^{\circ}$ in the region).

Having separated the alongshore velocity component, the respective time series were low-pass filtered (Butterworth) with a cutoff frequency of $(36 \mathrm{~h})^{-1}$ in order to exclude high-frequency processes such as inertial motions $\left[f \approx(30 \mathrm{~h})^{-1}\right]$ and tides from the analysis. The cutoff frequency marks a local gap in the spectrum and well separates the low-frequency part from the inertial band, as revealed by a spectral pre-examination of the data (not shown).

The velocity data are not continuous due to the maintenance of the moorings or a malfunctioning of devices. To ensure optimal continuity for the analysis of the data, 10 gaps shorter than 7 days in the low-pass-filtered time series were interpolated by splines. Moreover, one data gap of 26 days' length (LT18; 19 August-14 September 2014) was interpolated in the same manner. As a result, one continuous time series is obtained for LT20, and two time series are received at LT18 and LT23. The exact positions of the moorings and the dates of the time series are given in Table 1.

\section{b. Wind data}

Although a system of weather stations in southern Africa is under development under the SASSCAL program (http://www.sasscalweathernet.org/), stations along 
TABLE 1. Location of the moorings and dates of the velocity time series.

\begin{tabular}{|c|c|c|c|c|c|c|}
\hline Site & Series & Position & Depth (m) & Start & End & Duration (days) \\
\hline \multirow[t]{2}{*}{ LT18 } & 1 & $18^{\circ} \mathrm{S}, 11.65^{\circ} \mathrm{E}$ & 118 & 18 Sep 2013 & 30 Aug 2015 & 712 \\
\hline & 2 & $18^{\circ} \mathrm{S}, 11.65^{\circ} \mathrm{E}$ & 118 & 10 Nov 2015 & 7 Jun 2016 & 210 \\
\hline LT20 & 1 & $20^{\circ} \mathrm{S}, 12.75^{\circ} \mathrm{E}$ & 125 & 10 Jan 2014 & 20 Apr 2017 & 1196 \\
\hline \multirow[t]{2}{*}{ LT23 } & 1 & $23^{\circ} \mathrm{S}, 14.00^{\circ} \mathrm{E}$ & 132 & 3 Sep 2013 & 11 May 2016 & 980 \\
\hline & 2 & $23^{\circ} \mathrm{S}, 14.00^{\circ} \mathrm{E}$ & 132 & 11 Nov 2016 & 20 Apr 2017 & 160 \\
\hline
\end{tabular}

the southwest African coast are still rare. Therefore, in light of the scarce in situ wind data, we make use of a blended wind product (WIND_GLO_WIND_L4_NRT_ OBSERVATIONS_012_004) that combines remote observations (ASCAT) with 6-hourly analysis of the European Center for Medium Weather Forecasts (ECMWF; Bentamy and Fillon 2012). The data are on a $0.25^{\circ}$ Cartesian grid and were downloaded from the ftp server of the Copernicus Marine Environment Monitoring Service (ftp://nrt.cmems-du.eu/Core/). We calculated the alongshore wind stress according to the coastline azimuth and interpolated the data at a coastal distance of about $25 \mathrm{n} \mathrm{mi}(1 \mathrm{n} \mathrm{mi}=1.852 \mathrm{~km})$ to receive the coastal alongshore wind stress (referred to as coastal winds in the study).

\section{Low-frequency variability of the alongshore currents}

\section{a. The alongshore velocity signal}

An extract of the low-pass-filtered alongshore velocity time series at the three stations from October 2014 to August 2015 is shown in Fig. 2. A visual inspection of the data reveals three interesting features that are worth noting. First, the variance of the time series decreases remarkably toward higher latitudes. The vertically averaged variance of the low-pass-filtered alongshore velocity amounts to 237 (LT18), 57 (LT20), and $32 \mathrm{~cm}^{2} \mathrm{~s}^{-2}$ (LT23). Second, the current's direction is reversed seasonally. Currents are predominantly poleward (negative) at all sites in austral summer but are directed equatorward (positive) in the winter season. Flow reversals occur twice a year, around April-May and September-October, as recently shown by Junker et al. (2017). Finally, the data imply a connection of the alongshore velocity at the three sites on a subseasonal time scale. Certain events, such as the strong pulse of northward flow around the end of May 2015, occur almost simultaneously at all three stations. Particularly, this feature motivates the present study to a great extent.

To condense the spatiotemporal fields $(z-t)$ of the alongshore velocity component to a one-dimensional time series per station, the low-pass-filtered alongshore velocity fields were decomposed into ordinary empirical orthogonal functions (EOFs). The structure of the eigenfunctions, presented in Fig. 3, indicates that alongshore motion in the subinertial frequency range is essentially barotropic at all three stations (see also Fig. 2). The same finding was reported by Lass and Mohrholz (2005) for the site LT23. We point out that the explained variance of the first mode is greater than $91 \%$ across all stations (not shown). Thus, as the first mode dominates the low-frequency signal, it can be assumed to well represent the alongshore velocity variability at the mooring sites. Consequently, higher-order statistical modes are neglected in the analysis of this study, and the first-mode amplitude is henceforth referred to as the alongshore velocity (signal) for simplicity.

\section{b. Spectral characteristics of the alongshore velocity}

To account for the nonstationarity of the alongshore velocity and the transient nature of alongshelf-propagating waves, the spectral characteristics of the time series are investigated by means of wavelet methods following Torrence and Compo (1998). In contrast to Fourier methods, wavelet spectra allow us to investigate power fluctuations in the time and frequency domain at the same time.

The wavelet computation is performed on the individual continuous time series available at each station (Table 1). Besides the local wavelet power (Figs. 4a,c,e), we present temporal averages of the power of each time series, namely, the global wavelet power spectra (GWPS) in Figs. 4b, 4d, and 4f. We point out that each time series was normalized prior to the analysis such that the standard deviation equals one and the mean vanishes. Consequently, the presented wavelet power spectra are suited to compare the relative distribution of power at each station rather than comparing the power across the different sites. The total variance of the alongshore velocity signal decreases by about one order of magnitude from LT18 to LT23 (section 3a).

Besides notable differences in the temporal variability of the power at the three sites, the distribution of power with respect to frequency is very similar. A substantial portion of the energy is concentrated in an intermediatefrequency band spanning submonthly to subseasonal 


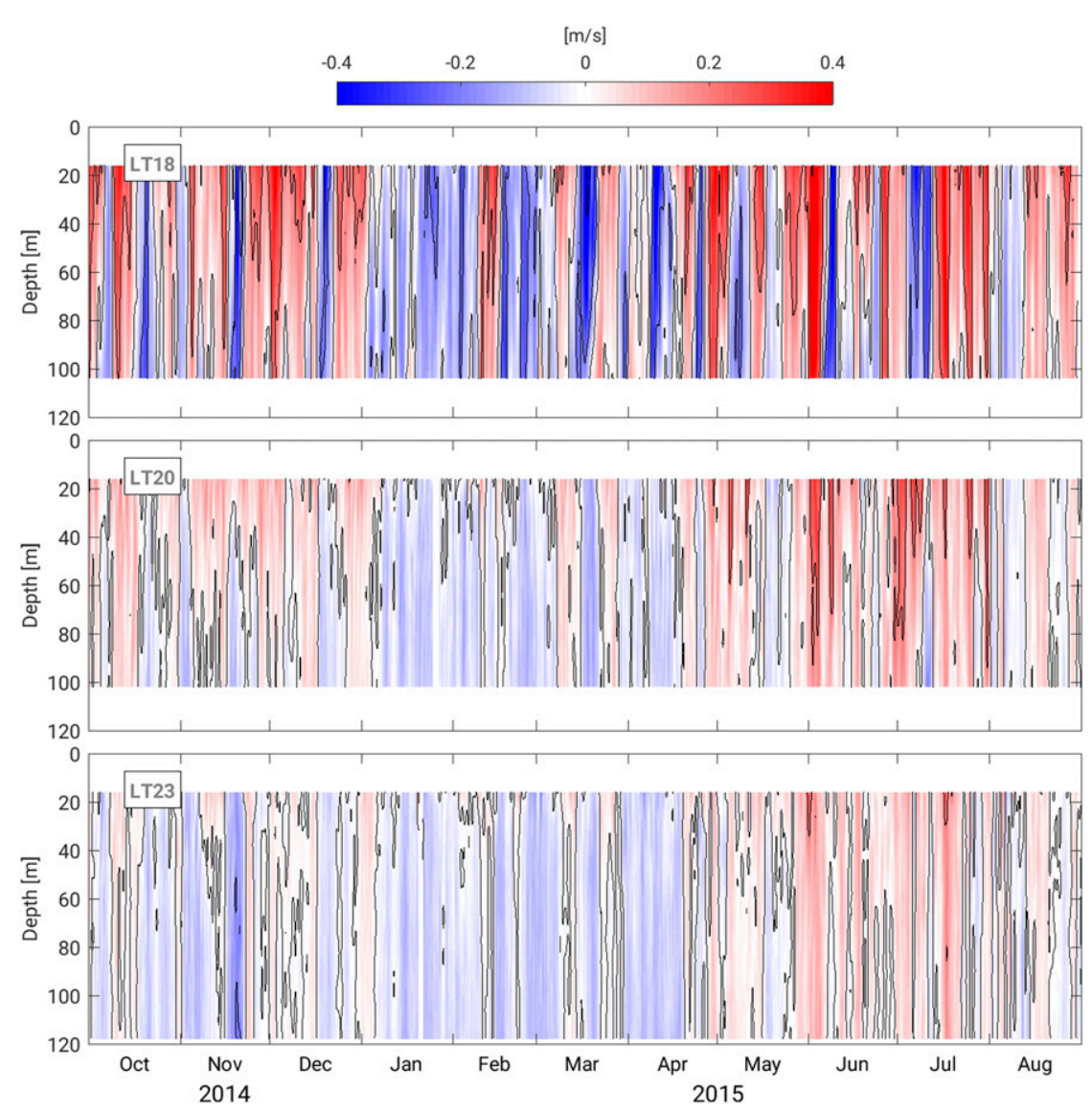

FIG. 2. Example time series of the low-pass-filtered $\left[f_{\mathrm{c}}=(36 \mathrm{~h})^{-1}\right]$ alongshore velocity at the three mooring sites from October 2014 to August 2015. Blue (red) color depicts poleward (equatorward) motion.

time scales (10-50 days). This band is embedded between the atmospheric synoptic variability (termed "weather band"; 2-10 days), characterized by shortterm events of high power, and the intraseasonal to seasonal variability ( $>50$ days). Note that the wavelet power is significant at the $5 \%$ level only up to about 50 days. Therefore, reliable statements about fluctuations on time scales beyond are hardly possible.

A drawback of wavelet methods in general is that they do not return spectra with identical peaks for signals with the same amplitude at different frequencies (Liu et al. 2007). However, the rectification of that bias proposed by Liu et al. (2007) seems not suitable for our data, as it would substantially distort the red character of the spectra. Instead, we use Fourier techniques as a complementary approach to the wavelet method in order to gain more confidence on the spectral properties of the alongshore currents. Furthermore, we limit the time series the Fourier spectrum is based on to the longest contemporaneous period of all sites (10 January 2014-30 August 2015; Fig. 4) to yield a consistent comparison of the energy distribution along the shelf. The Fourier spectrum (Fig. 5) verifies the major conclusions drawn from the wavelet spectrum. Most of the energy is concentrated between about 10 and 50 days, and energy drops dramatically at frequencies higher than $(10 \text { days })^{-1}$. Moreover, energy appears to be shifted from the intermediate-frequency band to lower frequencies from LT18 to LT23. The spectra at the different sites differ slightly within the intermediate-frequency band. Maxima in that band are seen at about 16 and 24 days (LT18 and LT20), while at LT23, energy is shifted to lower frequencies with maxima at 16 and 36 days. Notably, there is relatively high energy at around 8 days (LT23).

The strength of the wavelet method is to reveal the distribution of power not only in frequency, but also in time. Pronounced seasonal variations of power at all scales are visible in Fig. 4. At scales between 50 and 120 days, power attains a maximum at the end of each year (November-December) at all sites. An exception is given by the year 2016, when this maximum is missing. 

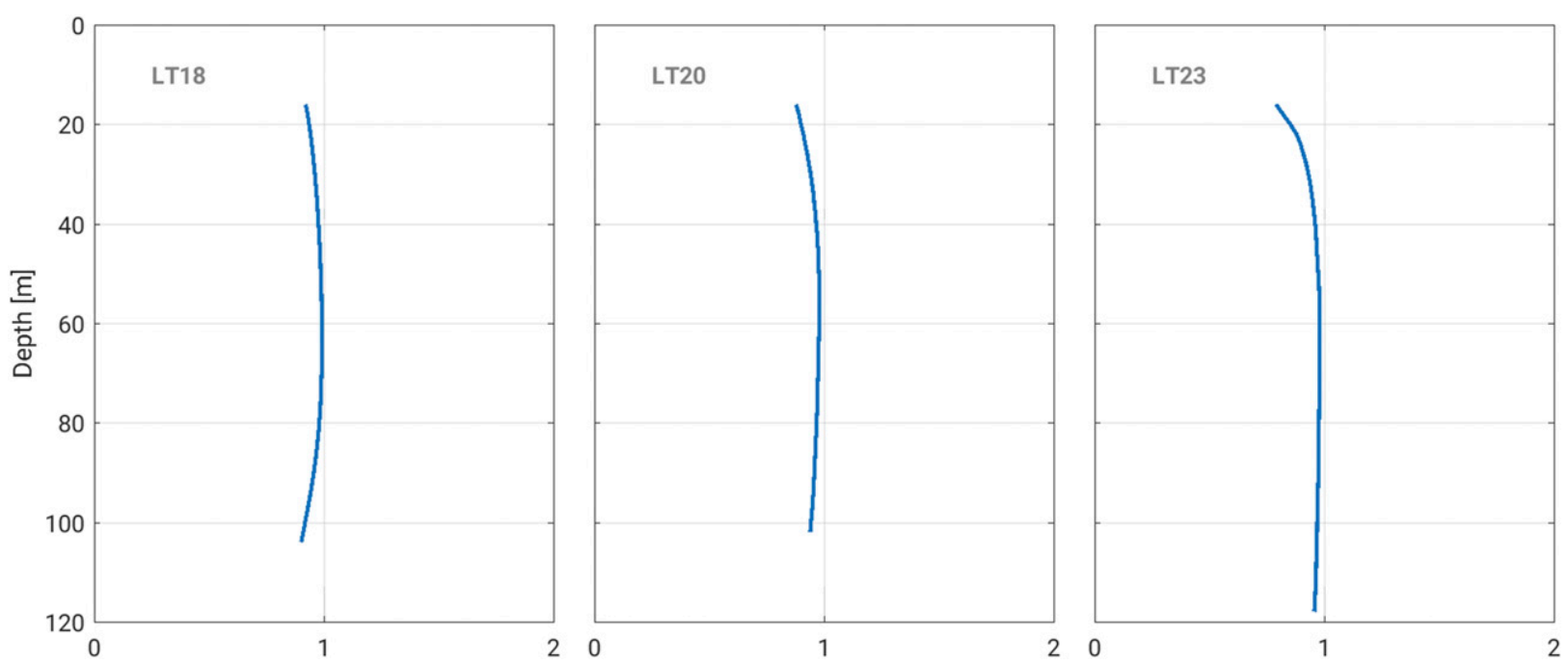

FIG. 3. First-mode EOF from the low-pass-filtered alongshore velocity at all three stations scaled by the square root of the associated eigenvalue. The variance explained by the first mode is about 0.92 for each station.

In the high-frequency weather band, the seasonal power distribution is not as obvious, but maxima seem to occur mostly in austral winter. The temporal variability of power in the most energetic frequency band (periods 10-50 days) is examined in more detail by averaging the wavelet power spectra across the associated scales. The result is presented in Fig. 6 by means of monthly mean values. A notable agreement in the temporal evolution of power is found between LT18 and LT20. In contrast, there is less agreement of LT18 and LT20 with the most southern station (LT23) for most of the time. Seasonal power maxima are seen in June, and potentially in April and October, whereby the seasonal range of power tends to decrease to the south. Besides, year-to-year variations seem very important, as demonstrated by the period of exceptional high power from April to August 2016 (LT20).

\section{Linear coherence between the mooring sites}

Based on the alongshore velocity signal, we have demonstrated similarities in the distribution of power among the three stations. In this section, we aim at investigating the coherence and phase relation along the Namibian shelf. For this sake, we define two coastal segments, S1 (between LT18 and LT20) and S2 (LT20 and LT23). Subsequently, we calculate the wavelet coherence and phase relation for both segments, as defined in the appendix of Torrence and Webster (1999). In doing so, the coherence analysis for each segment is restricted to two subseries depending on the concurrent data at hand (see Table 2). The significance of the coherence is tested by means of Monte Carlo methods according to Grinsted et al. (2004).
The wavelet coherence and phase spectra for the two segments are presented in Fig. 7. Positive (negative) phase lag is defined such that the signal at the northern station leads (lags) the signal at the southern site. In the highfrequency weather band (2-10 days), significant coherence is related to short-term events (duration of days to about 2 months) for both segments. The phase difference is most of the time positive with values ranging roughly between $-\pi / 4$ and $\pi / 2$. Events of strong significant coherence across the weather band are noted from June to August (2014 and 2015; S1 and S2). In the intermediate-frequency band, events of significant coherence last up to several months (S1 and S2). Notable exceptions are given by the periods from July to October 2014 (S1) and from July to August 2015 (S2), when coherence is almost absent. The phase difference is remarkably steady for both segments and reaches higher values for S1 (up to $\pi / 2$ ) than for S2 (up to $\pi / 4$ ) in the intermediate-frequency band. Apparently, events of very high coherence at S2 (e.g., October 2014 and February 2016) are associated with almost zero phase lag. For frequencies lower than $(50 \text { days })^{-1}$, significant coherence is observed for almost the whole time in a band centered at 64 days (S2). In the northern segment (S1), coherence vanishes with the beginning of 2015 in a band ranging from about 45 to 128 days.

To further quantify the coherence between the sites, we refer to local maxima in the coherence spectra that exceed the 95\% confidence level (Fig. 7). Each of these maxima represents a significant coherent event (SCE) that is characterized by its period (frequency) and phase lag. The resulting period-phase lag pairs are plotted in Figs. $8 \mathrm{a}$ and $8 \mathrm{c}$ for both segments. Apparently, the number of coherent events is slightly higher for S2 since the 


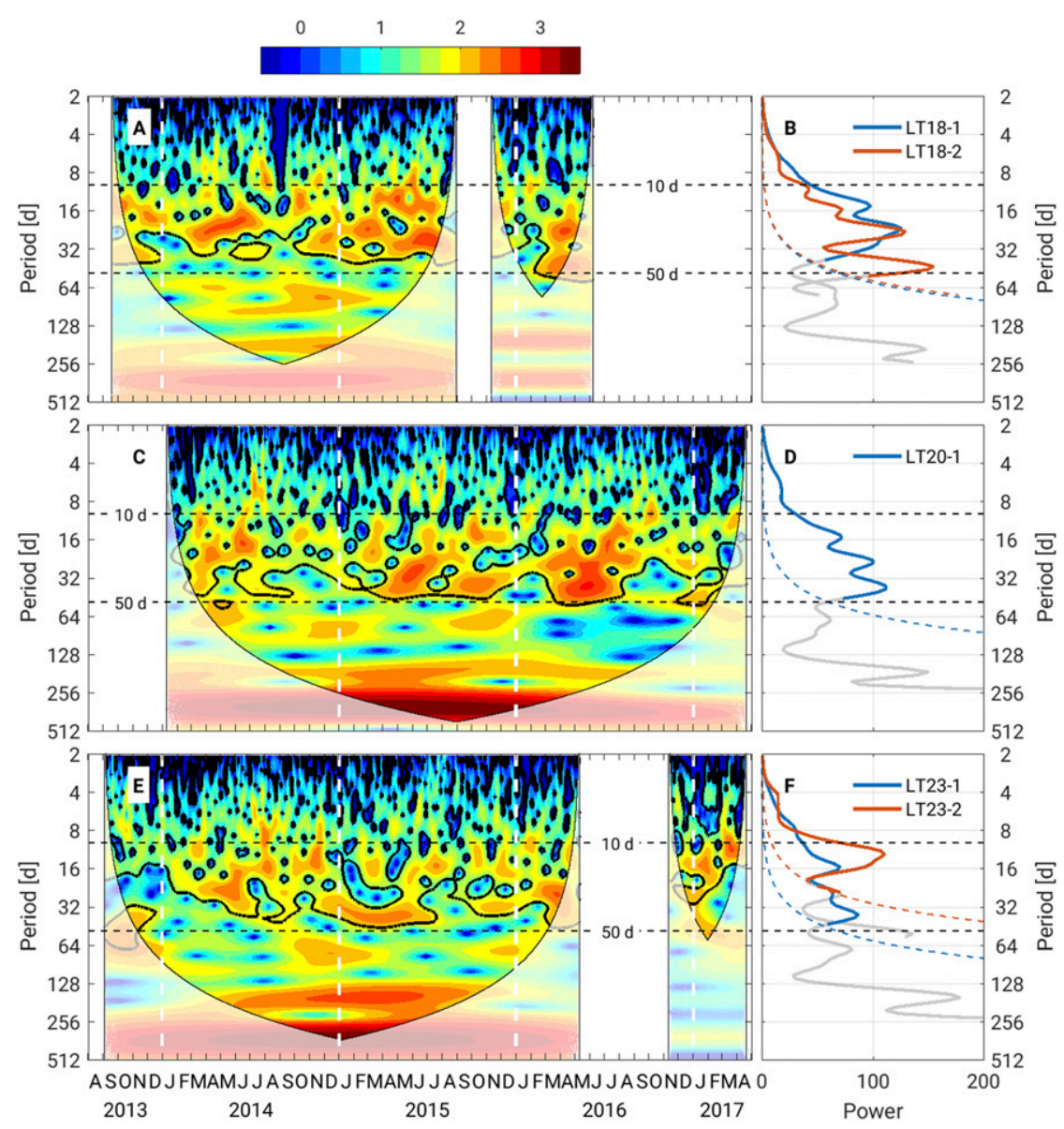

FIG. 4. (a) Wavelet power spectrum of the alongshore velocity signal for LT18 using the Morlet wavelet. Units are variance of the time series, and the color bar is logarithmically scaled. The black contours indicate the $95 \%$ confidence level against a red noise spectrum. The cones of influence are illustrated for each of the analyzed periods. Note that the time period of very low power between August and September 2014 (periods 2-16 days) results from the interpolation of a large data gap (26 days). (b) GWPS for the two series LT18-1 and LT18-2. The dashed lines indicate the significance at the 5\% level. (c),(d) As in (a) and (b), but for LT20. (e),(f) As in (a) and (b), but for LT23.

contemporaneous period between L20 and L23 is longer than between LT18 and LT20 (Table 2). And, moreover, the number of SCEs decreases to higher periods as coherent events last longer at these time scales. We note that most of the SCEs are characterized by a positive phase lag that is indicative of a southward wave propagation, whereby the sense of propagation is in accordance with that of left-bounded CTWs in the Southern Hemisphere. The wavenumber associated with the SCEs can be estimated from the phase lag by dividing through the distance between the two stations $\kappa(\omega)=\phi(\omega) \Delta y^{-1}$. This approach eliminates the difference in length between the two segments and makes the phase relation of the involved stations comparable. Subsequently, we estimate the wave's phase speed from the wavenumber and the associated frequency by $c=\omega \kappa^{-1}$.
The accuracy in measuring the phase difference of a signal between two stations (and consequently in determining its wavelength) is certainly limited by the accuracy of the instruments. If the wavelength becomes very long compared to the distance between the two sites, the difference of the amplitudes falls below the accuracy of the instruments. A rough estimate reveals that wavelengths larger than $10^{4} \mathrm{~km}$ cannot be resolved by the mooring setup (not shown). We note that waves at these spatial scales exceed the dimension of the South Atlantic by far. Thus, it is open to question whether fluctuations at these scales should be reasonably interpreted in terms of CTWs at all. Based on these considerations, we only take into account those coherent events with $\kappa \geq\left(10^{4} \mathrm{~km}\right)^{-1}$ and refer to them as "waves" instead of SCEs. 


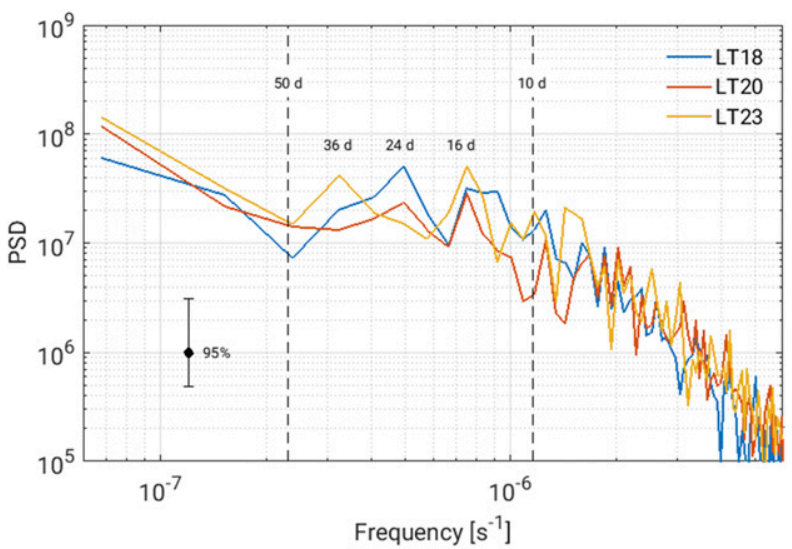

FIG. 5. PSD of the alongshore velocity signal at all three stations for the contemporaneous time period 10 Jan 2014-30 Aug 2015. The spectra were band averaged, resulting in about 10 effective degrees of freedom. The confidence interval applies to all spectra and frequencies.

Frequency-wavenumber pairs of the observed waves are presented in Figs. 8b and 8d. As surmised already from the wavelet phase relation (Figs. 7b,d), there appear to be remarkable differences between the two segments with regard to basic wave properties. To further quantify this finding, we calculate the wavelength and phase speed for each wave event by $\lambda=\kappa^{-1}$ and $c=\omega \kappa^{-1}$. Moreover, we bin the detected waves into three frequency bands $(2-10,10-50$, and $>50$ days; Figs. 8b,d) that relate to those identified in the wavelet power spectra (Fig. 4). Subsequently, we estimate a mean wavelength and a mean phase speed for each frequency band and each segment (Table 3). Besides, we provide high (low) values corresponding to plus (minus) one standard deviation from the mean. Table 3 demonstrates that in the southern segment, mean wavelengths and phase speeds are consistently higher than in the northern section. In the high energetic intermediate-frequency band (10-50 days), wavelengths and phase speeds between $20^{\circ}$ and $23^{\circ} \mathrm{S}$ are about twice as high as those between $18^{\circ}$ and $20^{\circ} \mathrm{S}$.

Having established basic CTW properties from the alongshore velocity time series, we compare these values to theoretical estimates. It is well known that wave forms and propagation speeds of CTWs are basically governed by the shelf geometry and the degree of stratification (e.g., Brink 1991). The relative effects of stratification and shelf geometry on CTWs are illustrated by the nondimensional Burger number $B=$ $N^{2} H^{2}\left(f^{2} L^{2}\right)^{-1}$ that results from scaling the vorticity equation (e.g., Brink 1991). Here, $H$ is the deep-sea depth, $L$ is the shelf-slope width, $N$ is the buoyancy frequency, and $f$ is the Coriolis parameter. Alternatively, $B$ can be expressed as the ratio of internal Rossby radius of deformation to the shelf-slope width $L$. Stratification becomes important when the internal Rossby radius clearly exceeds the cross-shelf scale (i.e., $B \gg 1)$. Using mean Rossby radii for the study area (Houry et al. 1987; Chelton et al. 1998), we receive Burger numbers of $0.5\left(18^{\circ} \mathrm{S}\right), 0.04\left(20^{\circ} \mathrm{S}\right)$, and 0.02 $\left(23^{\circ} \mathrm{S}\right)$. Thus, the effect of stratification on CTWs at the two southernmost sites is negligible since $B \ll 1$. In contrast, this effect might play a considerable role at $18^{\circ} \mathrm{S}$ as the Burger number is of order one. However, a detailed examination of the effect of stratification on CTWs from our observational dataset is difficult to undertake. The main reason is that we lack a sufficient number of density profiles and information about the currents in the surface layer. Nevertheless, the first mode from the EOF analysis indicates that the currents are basically barotropic at all three mooring sites. We are therefore quite confident that the observed waves are shaped by the shelf geometry rather than by stratification. Consequently, we refer to the simplest

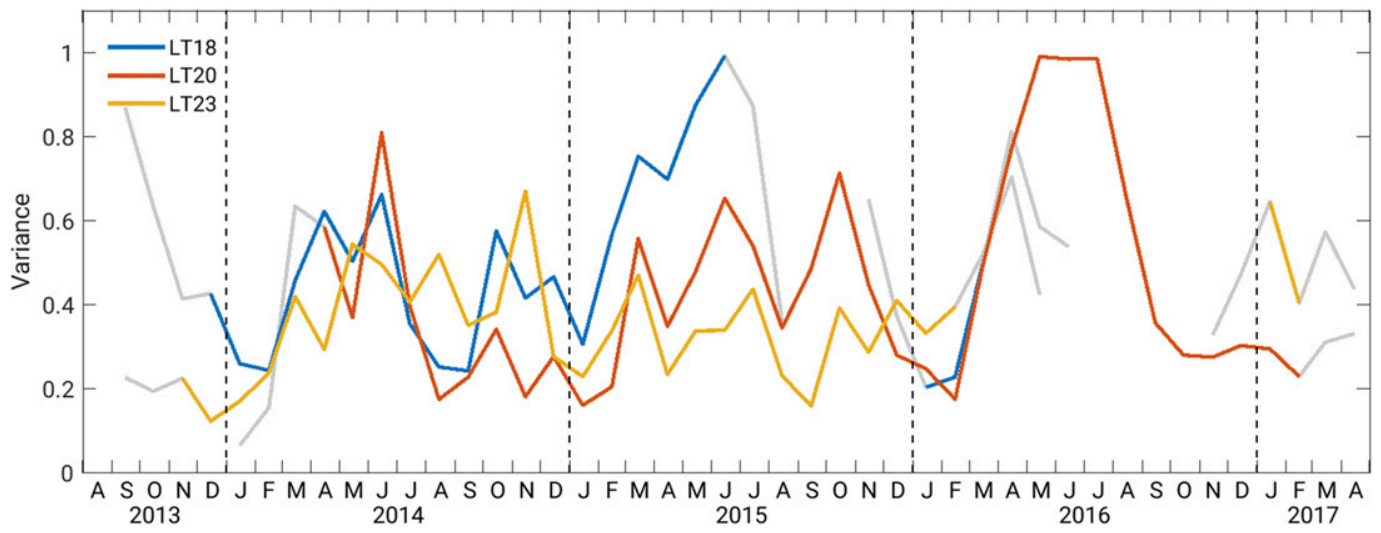

FIG. 6. Monthly means of the scale-averaged wavelet power in the high energetic intermediate-frequency band (periods 10-50 days) at the three stations. The first and last 50 days of each time series are colored gray in accordance with the cones of influence (Fig. 4). 
TABLE 2. Coastal segments and periods of time used for the wavelet coherence analysis.

\begin{tabular}{ccccccc}
\hline \hline Segment & Sites & Distance $(\mathrm{km})$ & Series & Start & End & Duration (days) \\
\hline S1 & LT18, LT20 & 250 & A & 10 Jan 2014 & 30 Aug 2015 & 598 \\
& & & B & 11 Nov 2015 & 6 Jun 2016 & 209 \\
S2 & LT20, LT23 & \multirow{2}{*}{350} & A & 10 Jan 2014 & 11 May 2016 & 852 \\
& & & B & 11 Nov 2016 & 20 Apr 2017 & 160 \\
\hline
\end{tabular}

formalism of CTWs that takes into account cross-shelf variations of the topography but neglects stratification: the barotropic continental shelf wave (CSW) model (Robinson 1964; Buchwald et al. 1968). To estimate the characteristics of these waves, we make use of MATLAB routines provided by Kaoullas and Johnson (2010) that calculate the dispersion relation of barotropic, nondivergent shelf waves over real topography numerically.

As seen from Fig. 1, the bottom topography in the region under study varies substantially with latitude. The shelf widens drastically from about $40 \mathrm{~km}$ at $18^{\circ} \mathrm{S}$ to about $100 \mathrm{~km}$ at $20^{\circ} \mathrm{S}$. South of that latitude, crossshelf topography is rather homogeneous. To investigate the role of this variation for the wave characteristics, we use cross-shore topographic profiles averaged between the mooring pairs (Fig. 9a) to calculate dispersion relations for the northern and southern segments (Fig. 9b). The dispersion curve associated with the northern segment (S1) yields considerably higher wavenumbers (shorter wavelengths, lower phase speeds) than those for the southern segment (S2) for the same mode and comparable frequencies. This peculiarity is mirrored in the characteristics of the observed waves. Especially for frequencies lower than $(10 \text { days })^{-1}$, wavenumbers are consistently smaller in the southern section (Figs. 8b,d, 9b). The observed wavenumbers and frequencies are in accordance with those of the first to third modes at the respective latitude. Waves at higher frequencies
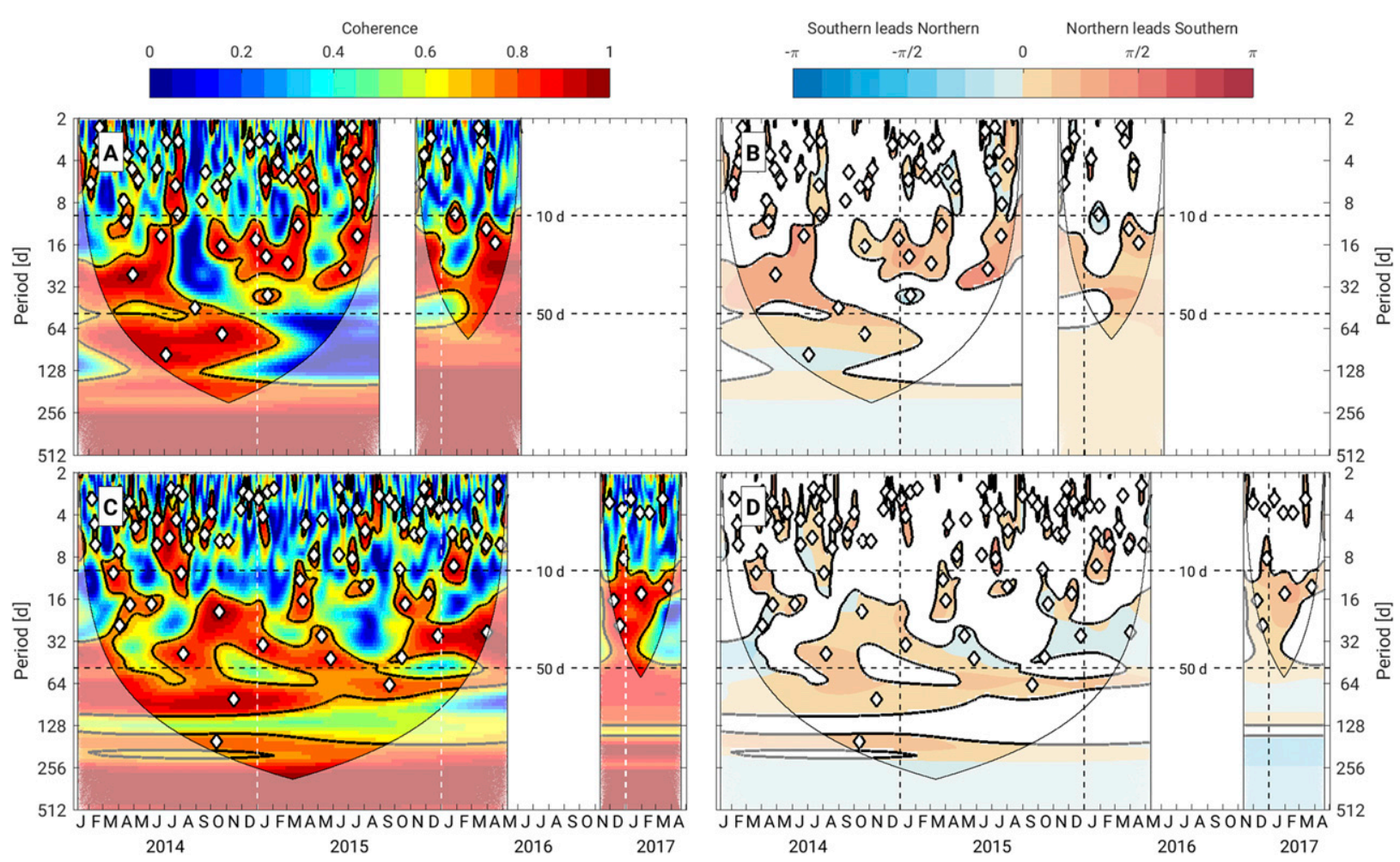

FIG. 7. (a) Wavelet coherence spectrum of the alongshore velocity signal for the northern segment S1 (LT18 and LT20). White markers indicate significant local maxima of the coherence. Black contours highlight the $95 \%$ confidence level. The cones of influence are illustrated. (b) Wavelet phase spectrum of the alongshore velocity signal for S1. For clarity, phase angles are drawn for periods of significant coherence only. (c),(d) As in (a) and (b), but for the southern segment S2. Positive phase difference is defined such that the signal at the northern station leads the southern. 


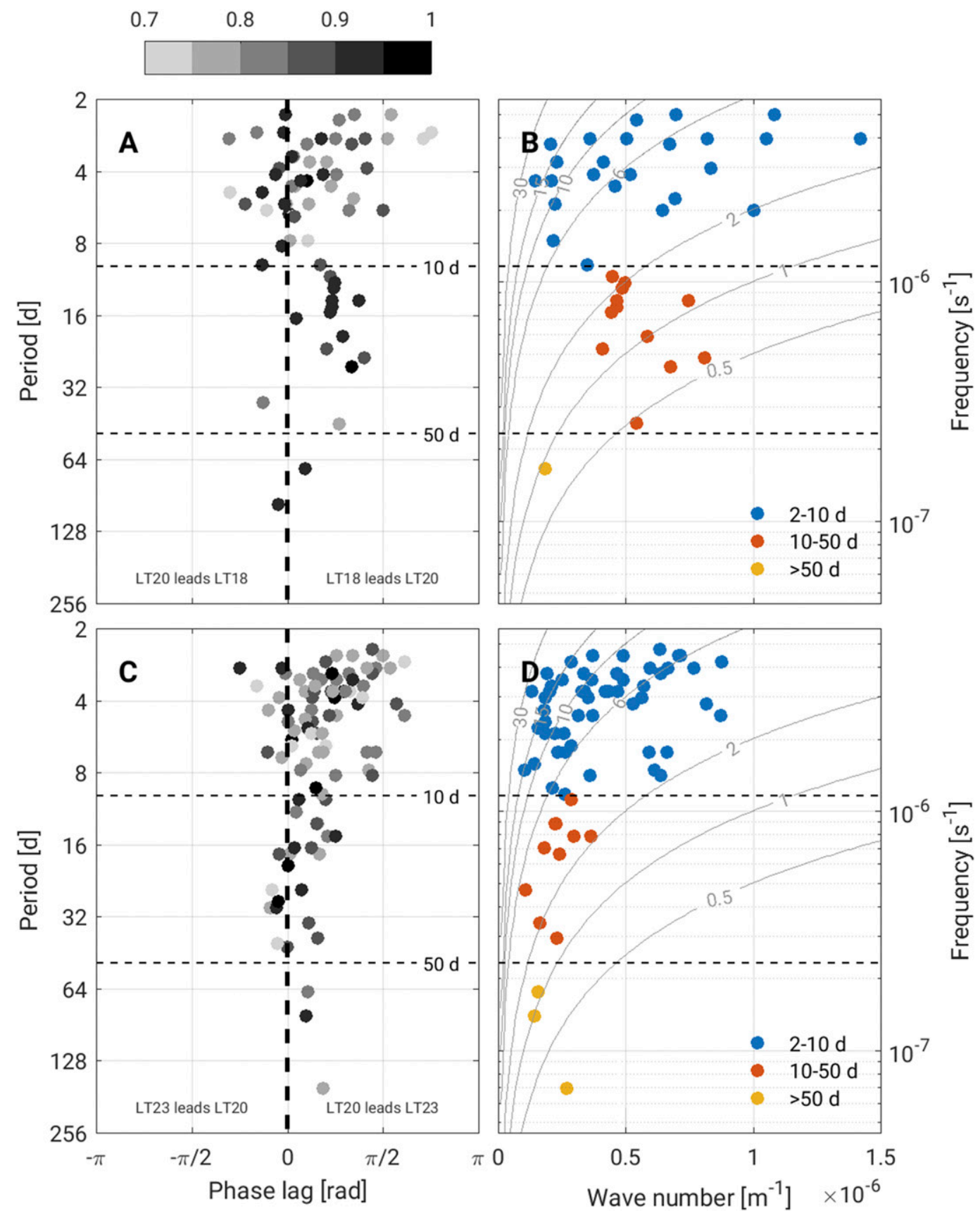

FIG. 8. (a) Period-phase relation of SCEs defined as local maxima in the wavelet coherence spectrum of S1 (Fig. 7). Shades of gray indicate the coherence associated with these events. (b) Frequency-wavenumber relation of southward-propagating waves for S1. Gray contours indicate the phase speed ( $\mathrm{m} \mathrm{s}^{-1}$ ). (c),(d) As in (a) and (b), but for the southern segment S2.

$\left[>(10 \text { days })^{-1}\right]$ partly exhibit lower wavenumbers than predicted by the theoretical dispersion curves, which might be attributed to the simplicity of the shelf wave model. However, alongshore motion at high frequencies appears to be energetically less relevant than that in the intermediate band.
In summary, the observed wave parameters fit well to the theoretical dispersion relations of barotropic continental shelf waves. In particular, the variation in shelf width can explain the observed differences of the properties of alongshelf-propagating waves in the two segments. 
TABLE 3. Mean wavelengths and phase speeds for three frequency bands estimated from SCEs (Fig. 8). High (low) values of the wavelengths and the phase speeds correspond to plus (minus) one standard deviation from the mean.

\begin{tabular}{|c|c|c|c|c|c|c|c|c|}
\hline \multirow[b]{2}{*}{ Segment } & \multirow[b]{2}{*}{ Band (days) } & \multirow[b]{2}{*}{ No. SCEs } & \multicolumn{3}{|c|}{ Wavelength (km) } & \multicolumn{3}{|c|}{ Phase speed $\left(\mathrm{m} \mathrm{s}^{-1}\right)$} \\
\hline & & & $\lambda_{\text {low }}$ & $\lambda$ & $\lambda_{\text {high }}$ & $c_{\text {low }}$ & $c$ & $c_{\text {high }}$ \\
\hline \multirow[t]{3}{*}{ LT18-LT20 } & $2-10$ & 25 & 809 & 2454 & 4098 & 2.6 & 7.2 & 11.7 \\
\hline & $10-50$ & 12 & 1521 & 1908 & 2296 & 0.8 & 1.4 & 2.0 \\
\hline & $>50$ & 1 & - & 5459 & - & - & 0.9 & - \\
\hline \multirow[t]{3}{*}{ LT20-LT23 } & $2-10$ & 53 & 1380 & 3237 & 5094 & 4.2 & 8.8 & 13.5 \\
\hline & $10-50$ & 10 & 2913 & 4805 & 6698 & 2.1 & 3.1 & 4.1 \\
\hline & $>50$ & 3 & 3945 & 5756 & 7568 & 0.3 & 0.8 & 1.3 \\
\hline
\end{tabular}

\section{Coherence between the alongshore velocity and the wind}

\section{a. Spectral characteristics of the coastal wind}

Both theoretical considerations and observations have established that fluctuations in the alongshelf velocity are most efficiently generated by transient alongshore winds that affect a limited area of the coast (Csanady 1997; Fennel 1999).

The large-scale wind forcing in the northern BUS is characterized by the strong southeasterly trade winds. The strength of these winds is not homogeneous along the African coast, and small-scale $[\mathscr{O}(100) \mathrm{km}]$ features of intensified or decreased wind stress exist (e.g., Fennel et al. 2012). The power spectral density (PSD) of the coastal wind is shown in Fig. 10a along the latitude between $10^{\circ}$ and $29^{\circ} \mathrm{S}$. The power spectrum comprises two alongshelf maxima centered at about $17.5^{\circ}$ and $26.5^{\circ} \mathrm{S}$. These coastal regions are referred to as the Kunene (Cape Frio) upwelling cell and the Lüderitz upwelling cell (Shannon 1985; Shannon and Nelson 1996). Wind power attains a minimum between both cells at about $22.5^{\circ} \mathrm{S}$ and decreases drastically in the tropical Angola upwelling system north of about $12^{\circ} \mathrm{S}$. In that region, wind power is about two orders of magnitude smaller than in the Cape Frio upwelling cell. Coastal winds are known to be very weak in that area year-round (Risien and Chelton 2008; Fennel et al. 2012).

The total variance of the wind stress at the mooring latitudes decreases from north to south (Fig. 10b), which is in accordance with the current's poleward energy decrease (Fig. 2). Concerning the distribution of energy in the frequency domain, the winds are quite homogeneous along the coast of the northern BUS. In particular at the mooring latitudes, peaks within the weather band ( 7 days) and the intermediate-frequency band (16, 26, and 40 days) are found at about the same periods (Fig. 10b).

We emphasize that peaks at comparable periods are portrayed in the currents' spectra (Figs. 4,5), suggesting a coupling of wind and currents at these time scales.
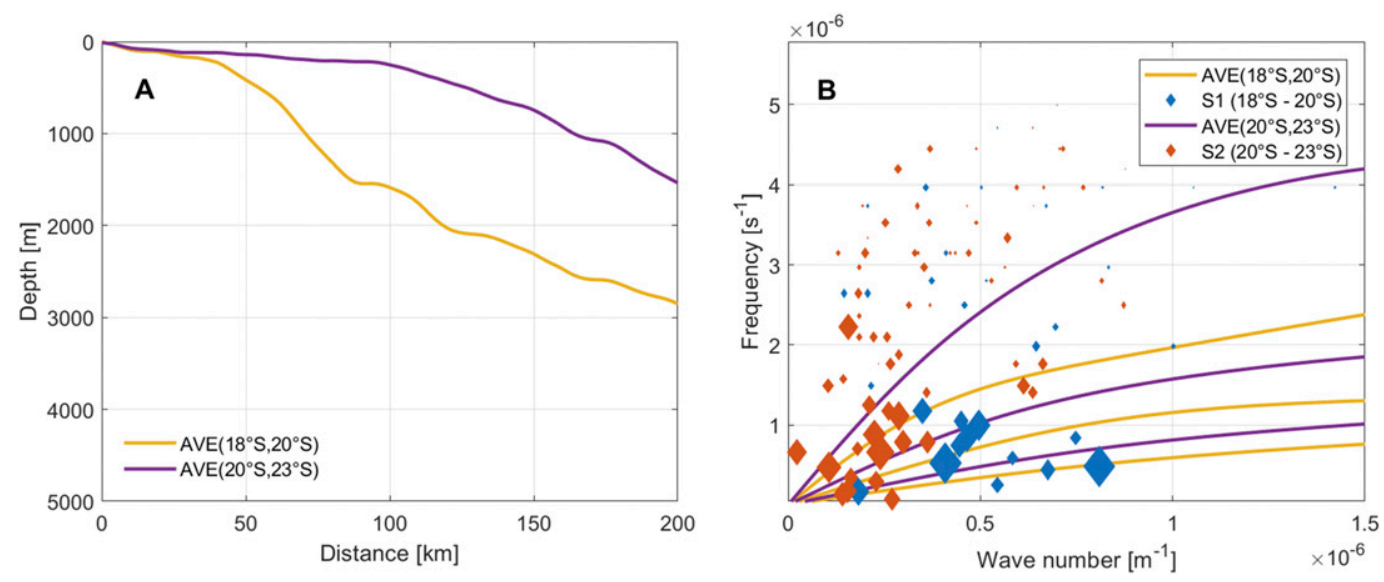

FIG. 9. (a) Cross-shelf topography averaged between each mooring pair. For clarity, only the first $200 \mathrm{~km}$ of the cross-shelf profiles are plotted. The offshore sections used for calculating the dispersion relations, however, extend $500 \mathrm{~km}$ offshore. (b) Comparison of the frequency-wavenumber relation of southward-propagating waves (dots) with the dispersion relation of barotropic CSWs (lines) derived from the averaged topographic profiles. The first three modes are shown, whereby the gravest mode is associated with the highest frequencies. The size of the dots scales with the wavelet power (Fig. 4) at the times the waves are observed. 

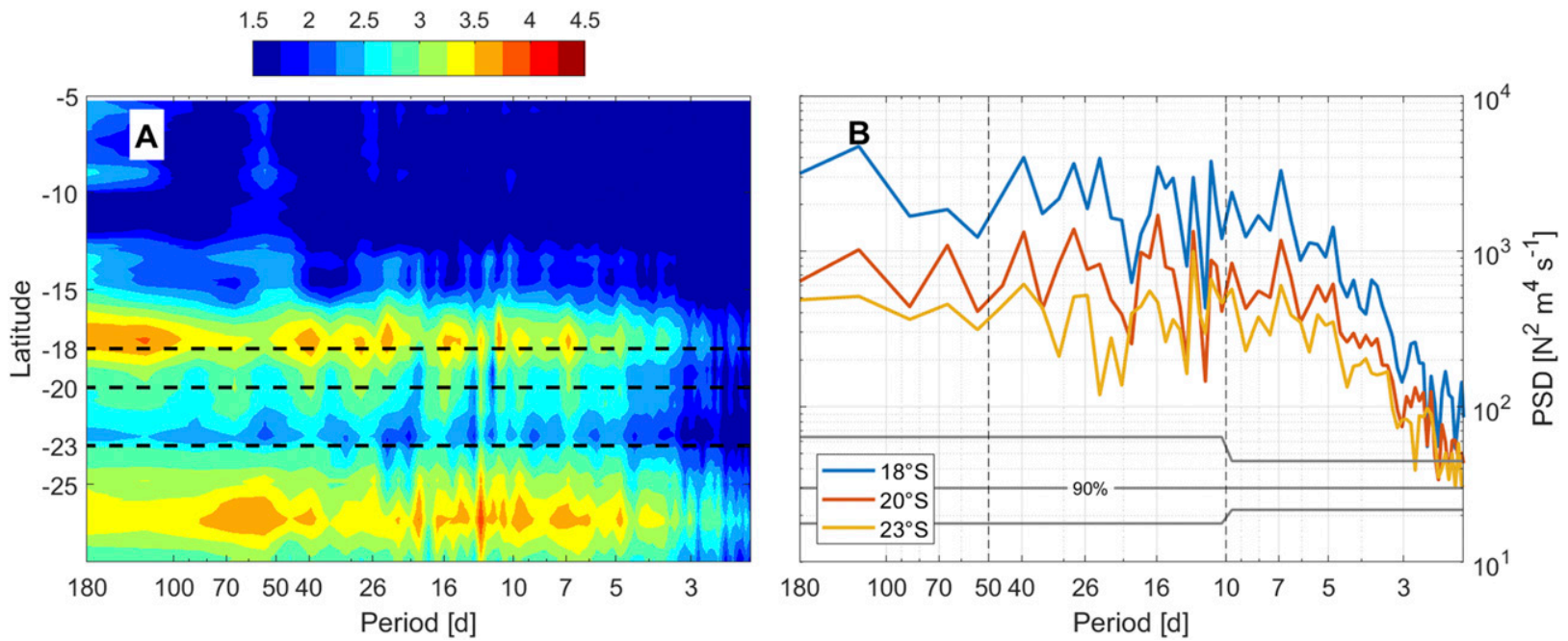

FIG. 10. (a) PSD of the near-coast alongshore wind stress at each latitude for time period 15 Nov 2012-31 Jul 2017. The color bar is logarithmically $\left(\log _{10}\right)$ scaled. The horizontal dashed lines mark the mooring latitudes. (b) PSD of the near-coast alongshore wind stress at the three mooring latitudes according to (a). The spectra were band averaged, resulting in 14 and 22 degrees of freedom. The $90 \%$ confidence interval applies to all spectra.

\section{b. Wind-current coherence}

The alongshore currents in the Benguela region are forced by coastal winds and are potentially also governed by waves excited by wind stress in the equatorial region. Consequently, we investigate the coherence between the alongshore motion and the coastal and equatorial winds. We use the alongshore current's signal at LT20 exemplary for the three stations, as it provides the longest continuous time series among the three sites (Table 1). For that purpose, the alongshore velocity time series was resampled on the 6-hourly temporal grid of the wind stress. The resulting wind current Fourier coherence spectrum is presented together with lead/lag times calculated from the associated phase spectrum in Fig. 11. Notably, there is high coherence between the alongshore motion and the local wind in the weather band peaking at around 5 and 7 days. The currents lag the wind by about 1 day at these periods, which is comparable to the adjustment time of one inertial period. As expected, there is no coherence of the currents with the equatorial winds in the weather band (i.e., at the atmospheric synoptic scale). For periods higher than 10 days, coherence with the local winds is highest along bands between $15^{\circ}$ and $23^{\circ} \mathrm{S}$ that are centered at periods of $15,25,45$, and 70 days. These bands represent a coastal section in which the spectral properties of the wind regime are very similar (Fig. 10). Coherence maxima are always found in close proximity to (or slightly to the north of) $20^{\circ} \mathrm{S}$, and the corresponding delay of the currents with respect to the alongshore winds is in the range of 2-3 days. Most coherence of the alongshore currents with remote winds is found in the equatorial region between about $22^{\circ}$ and $7^{\circ} \mathrm{W}$ at bands centered at 33, 25, and 15 days. In contrast to the coastal winds, there is no particular coherence of the alongshore motion with the equatorial winds at periods of 45 and 70 days.

Similar results for the wind-current coherence are obtained for the two other stations (not shown), but temporal variations of the coherence seem to play a considerable role (Fig. 12). In the weather band, coherence between the alongshore currents and the coastal winds is most pronounced in austral winter. The temporal evolution of the coherence in the intermediate-frequency band is similar, although the seasonal cycle is not that pronounced (not shown). Year-to-year variations are most clearly seen for motion at periods around 120 days. While coherence at these periods is almost absent during the years 2014 and 2015, there is a significant coupling of the currents and the local winds for 2016. The coherence between the alongshore currents and the equatorial winds is very persistent at annual and semiannual time scales. Concerning lower periods, no clearly defined coherence pattern is found.

\section{Summary and discussion}

For the first time, we use multisite velocity observations from the Namibian shelf $\left(18^{\circ}, 20^{\circ}, 23^{\circ} \mathrm{S}\right)$ to investigate alongshore fluctuations of the velocity with respect to poleward-propagating coastal trapped waves (CTWs). A statistical decomposition of the alongshore 

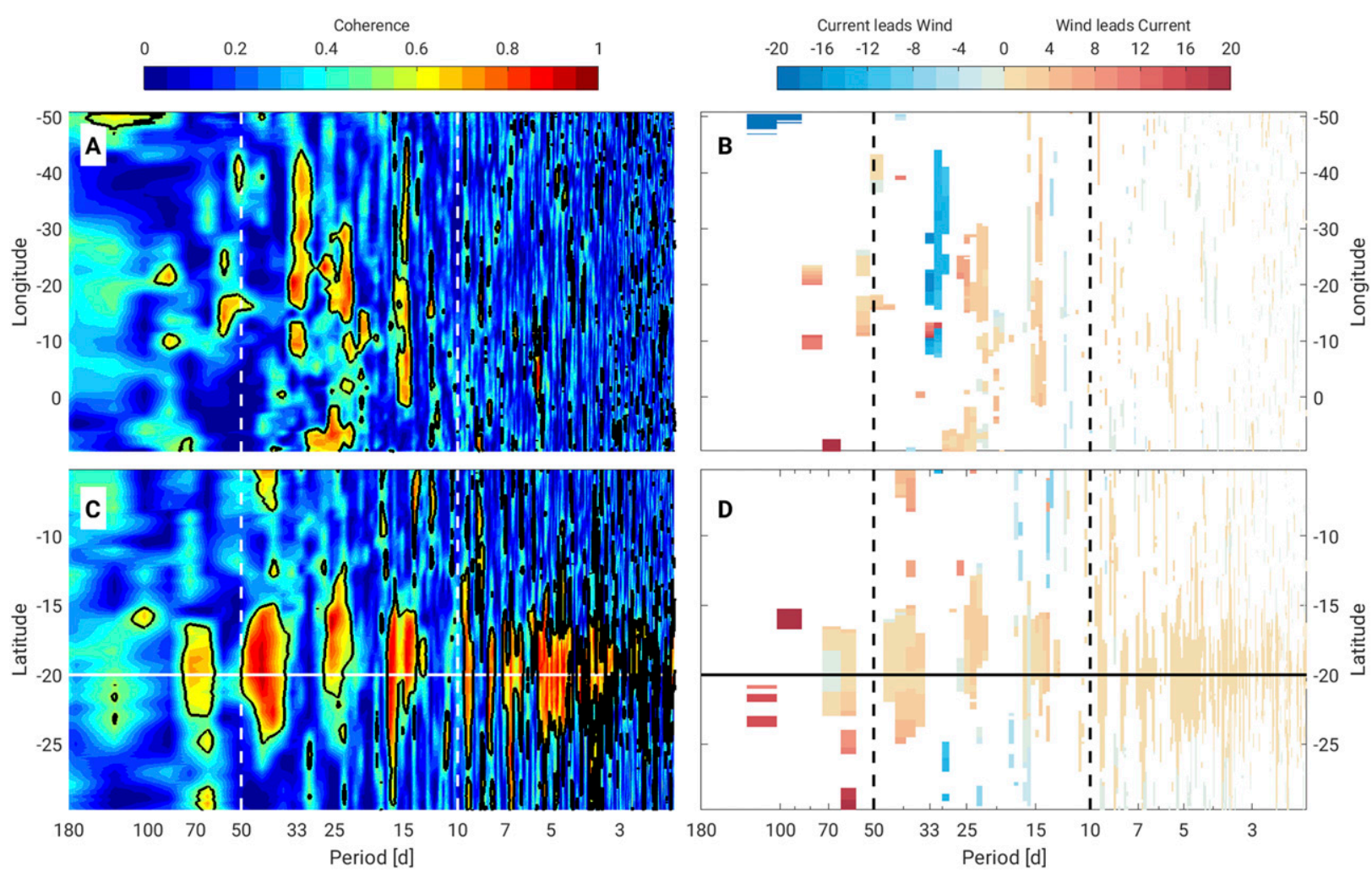

FIG. 11. (a) Fourier coherence spectrum of the alongshore velocity signal at LT20 and the wind stress magnitude along the equator. The thick black line indicates the $95 \%$ significance threshold (0.53) corresponding to the average of five realizations of the spectra (10 degrees of freedom; Thompson 1979). The vertical dashed lines enclose the intermediate-frequency band (10-50 days). (b) Time delay (days) calculated from the phase spectrum associated with (a). Wind leads (lags) currents at positive (negative) values. For clarity, we show only phase values that relate to significant coherence. (c),(d) As in (a) and (b), but showing the coherence with the wind stress along the southwest African coast. The horizontal dashed line indicates the mooring latitude $\left(20^{\circ} \mathrm{S}\right)$.

velocity field at each station yields a quasi-barotropic mode that accounts for more than $90 \%$ of the explained variance. The amplitudes of this mode, referred to as the alongshore velocity signal, are subjected to a spectral analysis by means of Fourier and wavelet methods.

The variance of the subinertial alongshore motion decreases by about one order of magnitude from $18^{\circ}$ to $23^{\circ} \mathrm{S}$ (Fig. 2). At all three sites, a major part of the energy is concentrated in an intermediate-frequency band spanning submonthly to subseasonal time scales between about 10 and 50 days (Figs. 4, 5). In that band, the most dominant spectral peaks appear around 16, 24, and 36 days. Our observations also demonstrate high energy at seasonal time scales, underlining the overall importance of the annual and semiannual cycle along the southwest African coast (Rouault 2012; Kopte et al. 2017; Junker et al. 2017). However, owing to the relative shortness of the single time series, the wavelet power of the alongshore motion is statistically significant at the $5 \%$ level only up to periods of about 50 days.
Concurrent periods of time over all three stations are used to investigate the latitudinal coherence of the alongshelf velocity in terms of CTW propagation in two coastal segments (S1 between LT18 and LT20; S2 between LT20 and LT23). Principal wave parameters are established from phase lags corresponding to local maxima in the coherence spectra. Based on this analysis, we conclusively demonstrate a southward phase propagation along the shelf of the northern Benguela system. Mean wavelengths range from about 1900 to $5700 \mathrm{~km}$, and the associated phase speeds vary between 0.8 and $8.8 \mathrm{~m} \mathrm{~s}^{-1}$ depending on the frequency of the waves (Table 3). Phase speeds estimated from altimetry data along the southwest African coast $\left[1.5-2.1 \mathrm{~m} \mathrm{~s}^{-1}\right.$ by Polo et al. (2008); about $0.75 \mathrm{~m} \mathrm{~s}^{-1}$ by Schouten et al. (2005)] fit well into that range. Wavelengths, periods, and phase speeds presented in this study are also in line with in situ observations at higher latitudes of the coast. Between Walvis Bay $\left(23^{\circ} \mathrm{S}\right)$ and Lüderitz Bay $\left(26.6^{\circ} \mathrm{S}\right)$, sea level propagation speeds from 10.1 to $15.9 \mathrm{~m} \mathrm{~s}^{-1}$ (de Cuevas et al. 1986) and around $5 \mathrm{~m} \mathrm{~s}^{-1}$ (Jury et al. 1990) were 

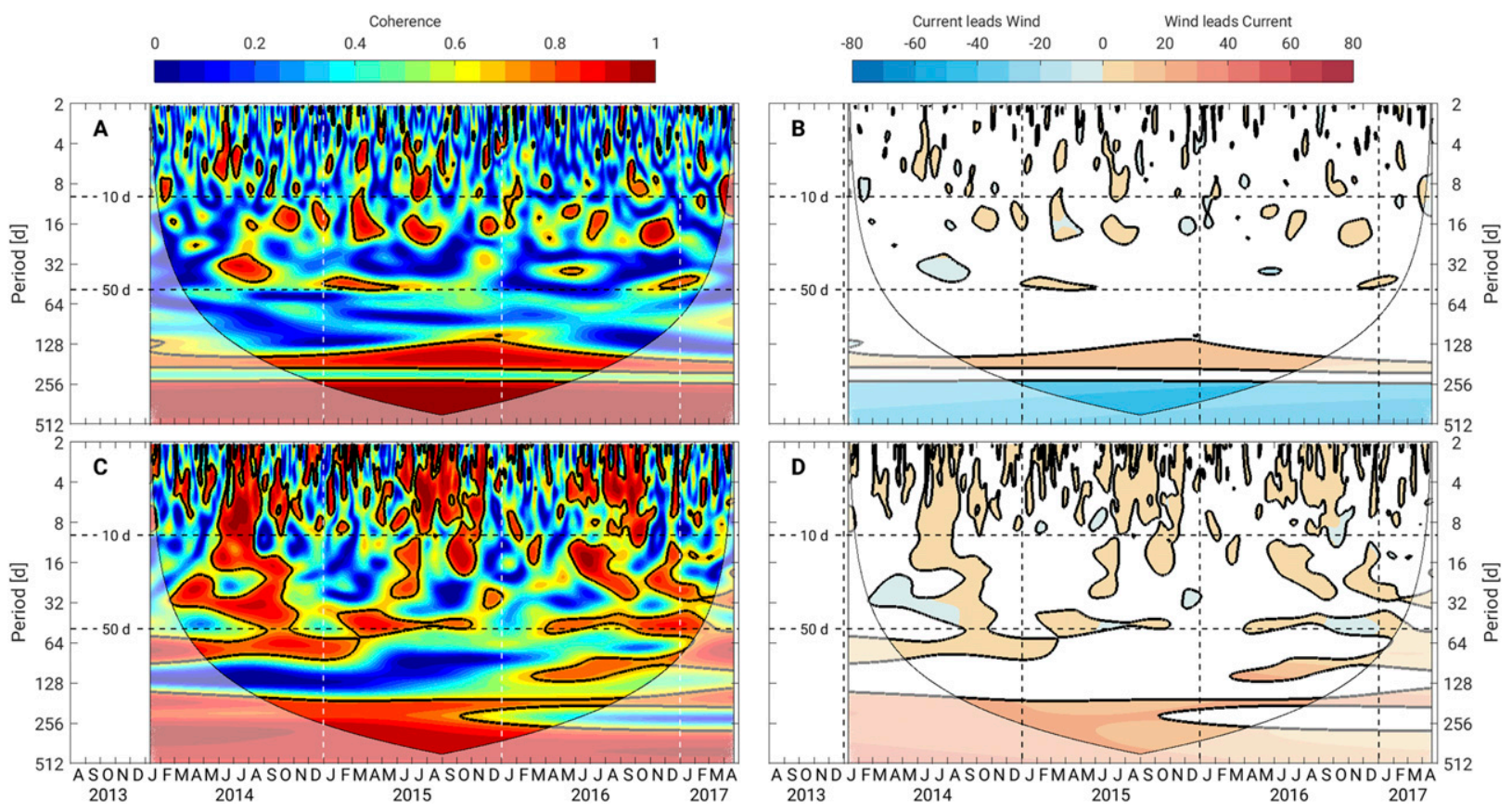

FIG. 12. (a) Wavelet coherence spectrum between the alongshore velocity signal at LT20 and the equatorial wind stress at $17^{\circ} \mathrm{W}$. Black contours indicate the $95 \%$ confidence level. (b) Lead/lag spectrum (days) according to (a). Positive values indicate that the wind leads the currents. (c),(d) As in (a) and (b), but for the alongshore wind stress at $20^{\circ} \mathrm{S}$.

reported. However, both studies do not reveal the periods of the propagating signals, which hampers a comparison to our results. Schumann and Brink (1990) found a significant propagation at the 14.8-day cycle with phase speeds of $2.7-3 \mathrm{~m} \mathrm{~s}^{-1}$ between Port Nolloth $\left(29.2^{\circ} \mathrm{S}\right)$ and Cape Town $\left(33.9^{\circ} \mathrm{S}\right)$. Likewise, Holden (1987) reported maximum coherence of the alongshore currents at periods of 16-17 days in the same coastal region with wavelengths and propagation speeds being greater than $1800 \mathrm{~km}$ and $1.8 \mathrm{~m} \mathrm{~s}^{-1}$, respectively. In accordance with these results, we found an accumulation of coherent events at periods around 15 days in both segments (Fig. 8). Propagating patterns at a comparable time scale (14.7 days) were also observed by Picaut and Verstraete (1979) in the Gulf of Guinea. Clarke and Battisti (1983) proposed that this propagation may be interpreted as a mode-two CTW, most likely generated by the wind variability in the equatorial Atlantic (Guiavarc'h et al. 2008).

In the light of the minor role of stratification on the wave characteristics and the quasi-barotropic character of the dominating alongshore velocity mode (Fig. 3), the observed wave parameters are compared to those of barotropic continental shelf waves. These waves provide the simplest formalism of CTWs, taking into account realistic shelf profiles but neglecting stratification. We show that poleward-propagating waves appear to have characteristics comparable to the first, second, and third modes of barotropic continental shelf waves for periods higher than about 10 days. In contrast, waves in the weather band (2-10 days) predominantly exhibit frequencies higher than predicted by the model—especially at low wavenumbers. A comparison between the two segments reveals that we observe consistently longer wavelengths and higher phase speeds in the southern segment (between LT20 and LT23) as a consequence of lower phase lags at comparable frequencies (Figs. 8a,c). The latitudinal difference of the wave characteristics is consistent with the outcome of the simplified shelf wave model and is also in line with theoretical considerations (e.g., Huthnance et al. 1986). The wider shelf between $20^{\circ}$ and $23^{\circ} \mathrm{S}$ implies longer wavelengths and higher phase speeds. Thus, the observed differences in the wave parameters may be explained by the different shelf widths. However, we have to emphasize that the two-dimensional model assumes an idealized shelf, such that its geometry changes in propagation direction on scales large compared to the wavelength (WKBJ approximation). With regard to the inferred wavelengths, this requirement is certainly not met. Besides, processes like stratification, scattering into higher-order modes, mean flow, and bottom friction are not captured by the model. For these reasons, the results of the shelf wave model should be taken with caution.

Besides the prevailing southward phase propagation, we also observe a limited number of coherent events 
that are characterized by almost zero or even negative phase lag (i.e., northward phase propagation). These events are most frequently found in the weather band (Figs. 8a,c). In addition to the alongshelf wave propagation, coupling between the stations is certainly also mediated by atmospheric processes. We note that there are no indications for an alongshore propagation of wind perturbations (not shown). In contrast to the region around Cape Hope, the northern BUS is located outside the pathway of eastward-moving cyclones, and thus pressure fluctuations are generally weak in the study region. Nevertheless, it is conceivable that weak atmospheric disturbances move northwestward along the Namibian shelf together with the mean atmospheric advection. Consequently, negative phase differences in the alongshore motion may be attributed to northwardpropagating perturbations in the alongshelf wind stress. Coherence at zero phase lag is most likely caused by a synchronous wind forcing along the coast.

The frequency spectra of the wind stress parallel to the coast display considerable similarities between about $15^{\circ}$ and $24^{\circ} \mathrm{S}$. An alongshelf maximum of the wind power density is found at about $17.5^{\circ} \mathrm{S}$ in the Kunene/Cape Frio upwelling cells. To the south of that area, wind stress decreases drastically, which corresponds to the poleward decrease of variance of the alongshore currents. High energy in the coastal winds is found at periodicities between 7 and 120 days (Fig. 10). We have to admit that except for the 7-day periodicity, peaks in the spectrum seem indistinct from the background to a high degree of confidence. This fact is possibly attributed to the blending procedure (ASCAT + ECMWF) yielding a rather smooth energy distribution of the wind stress. Despite that, our results are in basic accordance with previous studies that reported a concentration of wind power at 8 and 40 days (Risien et al. 2004) and 7 and 60 days (Goubanova et al. 2013).

The alongshore currents are strongly coherent and basically in phase with the local wind forcing at submonthly to subseasonal time scales. The coherence is particularly high at time scales that correspond to the atmospheric synoptic scale of 3-10 days (Shillington 1998). We demonstrate also significant coherence of the alongshelf currents with wind stress in the equatorial region at narrow bands centered at 15,25 , and 33 days (LT20). The corresponding lead/lag times are on the order of a few days and thus comparable to the time lag between the currents and the local winds. Drawing conclusions simply from the corresponding lead/lag times of the currents with respect to the equatorial forcing is difficult. A dynamical linkage of currents at the study sites and the equatorial region is given by large-scale variations in the pressure field affecting likewise coastal and equatorial winds, or by waves excited by the wind stress in the tropical Atlantic guided along the equator and the coast, or by a mixture of both processes. None of these scenarios are evidenced by our results. We solely demonstrate that the time scales of the forcing in the equatorial region are partly similar to those of the response in the Benguela region. However, Guiavarc'h et al. (2008) have shown with model simulations that the equatorial dynamics can affect the variability along the African coast in terms of CTWs on rather short time scales of several days to weeks.

The power of the alongshore currents in the intermediate-frequency band peaks around June, and a minimum is attained around February. The same finding holds true for the weather band (periods $<10$ days). Since the majority of the wind power occurs in the northern Benguela region during austral winter (Risien et al. 2004; Goubanova et al. 2013), the coherence of the wind with the alongshore currents is significantly high in that season, being most evident in the weather band (Fig. 12).

The most basic limitation of this observational study results from the spatial and temporal coverage of the velocity data. Deduced wavelengths, for instance, are limited by the alongshore scale of the mooring array. Waves shorter than the distance between the moorings cannot be captured unambiguously. Moreover, the available data do not allow for information on the crossshelf structure of CTWs that in general appear to be two-dimensional with a modal maximum close to the shelf edge (Huthnance 1981). Long-term data sampling on wide areas of the Namibian shelf, however, is hardly feasible due to extensive fisheries. A further constraint of the study is given by the limited length of the continuous time series at the three sites. The analysis of velocity fluctuations in terms of CTWs strongly depends on the availability of concurrent data along the shelf. Downtimes of single instruments due to maintenance or malfunctioning significantly impede such a study. From the present data, reliable statements about wave fluctuations on seasonal to interannual time scales are hardly possible. We point out that there are no indications for seasonal differences in the occurrence of CTWs or their principle properties (not shown). We also admit that the reported periods of time are associated with rather normal conditions in the northern Benguela region in terms of outstanding warm events (Benguela Niños). An estimation of the contribution of CTWs to interannual variations of the Benguela ecosystem from in situ data is therefore still missing.

Limitations of the study attributed to the data resolution can be overcome by ocean general circulation models. Although most of the regional and global 
models suffer from deficits in modeling the eastern boundary region of the South Atlantic correctly, these models provide extensive datasets coherent in space and time.

In essence, the reported observations provide a dataset that is unique along the southwest African coast, and the study offers new insights into the properties of CTWs in the northern BUS. We found that wave characteristics evidently change within the Benguela region potentially caused by the inhomogeneous topography of the Namibian shelf. Additionally, we demonstrate that the dominant mode of the alongshore velocity is strongly coherent with the local winds on submonthly to subseasonal time scales.

Further attempts are needed to systematically investigate CTW dynamics between the equatorial Atlantic region and the Benguela system, including model studies that target changes in the two-dimensional modal structure and the energy dissipation of these waves along their path.

Acknowledgments. The work leading to this study was funded by the European Commission's Seventh Framework Programme (2007-13) under Grant Agreement 603521 (PREFACE) and the BMBF under the project "SACUS I/II." The deployment and maintenance of the LT23 mooring was financially supported by the Federal Ministry of Education and Research of Germany (BMBF) under the project GENUS II. We express our gratitude for the valuable work done by the captains and the crews of the R/V Maria S. Merian, R/V Meteor, R/V Mirabilis, and R/V Welwitschia during the various deployments of the moorings. A special thanks should be given to the technicians Günter Plüschke, Toralf Heene, and Sebastian Beier working at the Institut für Ostseeforschung Warnemünde (IOW). We thankfully acknowledge the longstanding logistical and scientific support by the National Marine Information and Research Centre (NatMIRC) in Swakopmund (Namibia). We greatly acknowledge the helpful comments and suggestions of two anonymous reviewers.

\section{REFERENCES}

Allen, J. S., 1980: Models of wind-driven currents on the continental shelf. Annu. Rev. Fluid Mech., 12, 389-433, https://doi.org/ 10.1146/annurev.fl.12.010180.002133.

Bachèlery, M.-L., S. Illig, and I. Dadou, 2016: Interannual variability in the South-East Atlantic Ocean, focusing on the Benguela Upwelling System: Remote versus local forcing. J. Geophys. Res. Oceans, 121, 284-310, https://doi.org/10.1002/2015JC011168.

Bentamy, A., and D. C. Fillon, 2012: Gridded surface wind fields from Metop/ASCAT measurements. Int. J. Remote Sens., 33, 1729-1754, https://doi.org/10.1080/01431161.2011.600348.
Brink, K. H., 1991: Coastal-trapped waves and wind-driven currents over the continental shelf. Annu. Rev. Fluid Mech., 23, 389-412, https://doi.org/10.1146/annurev.fl.23.010191.002133.

Buchwald, V. T., J. K. Adams, and M. S. Longuet-Higgins, 1968: The propagation of continental shelf waves. Proc. Roy. Soc. London, 305, 235-250, https://doi.org/10.1098/rspa.1968.0115.

Chelton, D. B., R. A. deSzoeke, M. G. Schlax, K. E. Naggar, and N. Siwertz, 1998: Geographical variability of the first baroclinic Rossby radius of deformation. J. Phys. Oceanogr., 28, 433-460, https://doi.org/10.1175/1520-0485(1998)028<0433: GVOTFB $>2.0 . \mathrm{CO} ; 2$.

Clarke, A. J., and D. S. Battisti, 1983: Identification of the fortnightly wave observed along the northern coast of the Gulf of Guinea. J. Phys. Oceanogr., 13, 2192-2200, https://doi.org/ 10.1175/1520-0485(1983)013<2192:IOTFWO>2.0.CO;2.

Csanady, G. T., 1997: On the theories that underlie our understanding of continental shelf circulation. J. Oceanogr., 53, 207-229.

de Cuevas, B. A., G. B. Brundrit, and A. M. Shipley, 1986: Lowfrequency sea-level fluctuations along the coasts of Namibia and South Africa. Geophys. J. Int., 87, 33-42, https://doi.org/ 10.1111/j.1365-246X.1986.tb04544.x.

Emery, W. J., and R. E. Thomson, 2014: Data Analysis Methods in Physical Oceanography. 3rd ed. Newnes, $728 \mathrm{pp}$.

Fennel, W., 1999: Theory of the Benguela Upwelling System. J. Phys. Oceanogr., 29, 177-190, https://doi.org/10.1175/15200485(1999)029<0177:TOTBUS $>2.0$. CO;2.

, T. Junker, M. Schmidt, and V. Mohrholz, 2012: Response of the Benguela upwelling systems to spatial variations in the wind stress. Cont. Shelf Res., 45, 65-77, https://doi.org/10.1016/ j.csr.2012.06.004.

Florenchie, P., J. R. E. Lutjeharms, C. J. C. Reason, S. Masson, and M. Rouault, 2003: The source of Benguela Niños in the South Atlantic Ocean. Geophys. Res. Lett., 30, 1505, https://doi.org/ 10.1029/2003GL017172.

Goubanova, K., S. Illig, E. Machu, V. Garçon, and B. Dewitte, 2013: SST subseasonal variability in the central Benguela upwelling system as inferred from satellite observations (1999-2009). J. Geophys. Res. Oceans, 118, 4092-4110, https:// doi.org/10.1002/jgrc.20287.

Grinsted, A., J. C. Moore, and S. Jevrejeva, 2004: Application of the cross wavelet transform and wavelet coherence to geophysical time series. Nonlinear Processes Geophys., 11, 561566, https://doi.org/10.5194/npg-11-561-2004.

Guiavarc'h, C., A. M. Treguier, and A. Vangriesheim, 2008: Remotely forced biweekly deep oscillations on the continental slope of the Gulf of Guinea. J. Geophys. Res., 113, C06002, https://doi.org/10.1029/2007JC004471.

Hagen, E., 1979: Zur Dynamik Charakteristischer Variationen mit Barotropem Charakter in Mesoskalen Ozeanologischen Feldverteilungen Küstennaher Auftriebsgebiete. Geodätische und geophysikalische Veröffentlichungen, $71 \mathrm{pp}$.

Holden, C. J., 1987: Observations of low-frequency currents and continental shelf waves along the west coast of South Africa. S. Afr. J. Mar. Sci., 5, 197-208, https://doi.org/10.2989/ 025776187784522360 .

Houry, S., E. Dombrowsky, P. De Mey, and J.-F. Minster, 1987: Brunt-Väisälä frequency and Rossby radii in the South Atlantic. J. Phys. Oceanogr., 17, 1619-1626, https://doi.org/ 10.1175/1520-0485(1987)017<1619:BVFARR >2.0.CO;2

Huthnance, J. M., 1981: Waves and currents near the continental shelf edge. Prog. Oceanogr., 10, 193-226, https://doi.org/10.1016/ 0079-6611(81)90004-5. 
— L. A. Mysak, and D.-P. D.-P. Wang, 1986: Coastal trapped waves. Baroclinic Processes on Continental Shelves, C. N. Mooers, Ed., Coastal and Estuarine Sciences, Vol. 3, Amer. Geophys. Union, 1-18, https://doi.org/10.1029/CO003p0001.

Junker, T., V. Mohrholz, L. Siegfried, and A. K. van der Plas, 2017: Seasonal to interannual variability of water mass fraction and currents on the Namibian shelf. J. Mar. Syst., 165, 36-46, https://doi.org/10.1016/j.jmarsys.2016.09.003.

Jury, M., C. Macarthur, and C. Reason, 1990: Observations of trapped waves in the atmosphere and ocean along the coast of southern Africa. S. Afr. Geogr. J., 72, 33-46, https://doi.org/ 10.1080/03736245.1990.10586373.

Kaoullas, G., and E. Johnson, 2010: Fast accurate computation of shelf waves for arbitrary depth profiles. Cont. Shelf Res., 30 , 833-836, https://doi.org/10.1016/j.csr.2009.12.010.

Kopte, R., P. Brandt, M. Dengler, P. C. M. Tchipalanga, M. Macuéria, and M. Ostrowski, 2017: The Angola Current: Flow and hydrographic characteristics as observed at $11^{\circ} \mathrm{S}$. J. Geophys. Res. Oceans, 122, 1177-1189, https://doi.org/10.1002/ 2016JC012374

Lass, H.-U., and V. Mohrholz, 2005: On the fluctuations and vertical structure of the shelf circulation off Walvis Bay, Namibia. Cont. Shelf Res., 25, 1473-1497, https://doi.org/ 10.1016/j.csr.2005.04.012.

Liu, Y., X. S. Liang, and R. H. Weisberg, 2007: Rectification of the bias in the wavelet power spectrum. J. Atmos. Oceanic Technol., 24, 2093-2102, https://doi.org/10.1175/ 2007JTECHO511.1.

Lübbecke, J. F., C. W. Böning, N. S. Keenlyside, and S.-P. Xie, 2010: On the connection between Benguela and equatorial Atlantic Niños and the role of the South Atlantic Anticyclone. J. Geophys. Res., 115, C09015, https://doi.org/10.1029/ 2009JC005964.

Picaut, J., and J. M. Verstraete, 1979: Propagation of a 14.7-day wave along the northern coast of the Guinea Gulf. J. Phys. Oceanogr., 9, 136-149, https://doi.org/10.1175/1520-0485(1979)009<0136: POADWA $>2.0$.CO;2.

Polo, I., A. Lazar, B. Rodriguez-Fonseca, and S. Arnault, 2008: Oceanic Kelvin waves and tropical Atlantic intraseasonal variability: 1 . Kelvin wave characterization. J. Geophys. Res., 113, C07009, https://doi.org/10.1029/2007JC004495.

Risien, C. M., and D. B. Chelton, 2008: A global climatology of surface wind and wind stress fields from eight years of QuikSCAT scatterometer data. J. Phys. Oceanogr., 38, 23792413, https://doi.org/10.1175/2008JPO3881.1.

, C. J. C. Reason, F. A. Shillington, and D. B. Chelton, 2004: Variability in satellite winds over the Benguela upwelling system during 1999-2000. J. Geophys. Res., 109, C03010, https://doi.org/10.1029/2003JC001880.

Robinson, A. R., 1964: Continental shelf waves and the response of sea level to weather systems. J. Geophys. Res., 69, 367-368, https://doi.org/10.1029/JZ069i002p00367.

Rouault, M., 2012: Bi-annual intrusion of tropical water in the northern Benguela upwelling. Geophys. Res. Lett., 39, L12606, https://doi.org/10.1029/2012GL052099.

_ , S. Illig, C. Bartholomae, C. Reason, and A. Bentamy, 2007: Propagation and origin of warm anomalies in the Angola Benguela upwelling system in 2001. J. Mar. Syst., 68, 473-488, https://doi.org/10.1016/j.jmarsys.2006.11.010.

,,-- J. Lübbecke, and R. A. I. Koungue, 2018: Origin, development and demise of the 2010-2011 Benguela Niño. J. Mar. Syst., 188, 39-48, https://doi.org/10.1016/j.jmarsys.2017.07.007.

Schouten, M. W., R. P. Matano, and T. P. Strub, 2005: A description of the seasonal cycle of the equatorial Atlantic from altimeter data. Deep-Sea Res. I, 52, 477-493, https://doi.org/ 10.1016/j.dsr.2004.10.007.

Schumann, E. H., and K. H. Brink, 1990: Coastal-trapped waves off the coast of South Africa: Generation, propagation and current structures. J. Phys. Oceanogr., 20, 1206-1218, https://doi.org/ 10.1175/1520-0485(1990)020<1206:CTWOTC > 2.0.CO;2.

Shannon, L. V., 1985: The Benguela ecosystem. Part I: Evolution of the Benguela: Physical features and processes. Oceanogr. Mar. Biol., 23, 105-182.

, and G. Nelson, 1996: The Benguela: Large scale features and processes and system variability. The South Atlantic-Present and Past Circulation, G. Wefer et al., Eds., Springer, 163-210.

Shillington, F., 1998: The Benguela Upwelling System off southwestern Africa. The Sea, M. N. Hill, Ed., Wiley, 583-604.

Thompson, R. O. R. Y., 1979: Coherence significance levels. J. Atmos. Sci., 36, 2020-2021, https://doi.org/10.1175/15200469(1979)036<2020:CSL>2.0.CO;2.

Torrence, C., and G. P. Compo, 1998: A practical guide to wavelet analysis. Bull. Amer. Meteor. Soc., 79, 61-78, https://doi.org/ 10.1175/1520-0477(1998)079<0061:APGTWA > 2.0.CO;2.

— , and P. J. Webster, 1999: Interdecadal changes in the ENSOmonsoon system. J. Climate, 12, 2679-2690, https://doi.org/ 10.1175/1520-0442(1999)012<2679:ICITEM>2.0.CO;2.

Vangriesheim, A., A. Marie Treguier, and G. Andre, 2005: Biweekly current oscillations on the continental slope of the Gulf of Guinea. Deep-Sea Res. I, 52, 2168-2183, https://doi.org/10.1016/ j.dsr.2005.05.010.

Woodworth, P., A. Aman, and T. Aarup, 2007: Sea level monitoring in Africa. Afr. J. Mar. Sci., 29, 321-330, https://doi.org/ 10.2989/AJMS.2007.29.3.2.332. 